\title{
The life of high-level athletes: \\ The challenge of high \\ performance against the \\ time constraint
}

\section{Fabrice Burlot}

National Institute of Sport, Expertise and Performance (INSEP), France

\section{Rémi Richard}

University of Montpellier, France

\section{Helene Joncheray}

Paris Descartes University - Sorbonne Paris Cité, France

\begin{abstract}
The conditions for high performance have changed considerably over the last few years. Athletes must spend more time training and competing, devote a lot of time to mental, physical and nutritional professionals and continue to respond to some constraints such as studying, spending time with their families, friends and quality of life. In this context and based on the work of Rosa, we wonder about the capacity of elite athletes to combine all these constraints, namely to manage the acceleration in their pace of life, in order to be able to achieve always more and better in the same time unit. To address this issue, we interviewed 42 French high-level athletes who train at the National Institute of Sport, Expertise and Performance (INSEP). Results show that to suit their goals, athletes implement arrangement and adjustment strategies aimed at making the time they have wholly useful and efficient. This time constraint puts athletes in a perpetual state of tension, on the verge of a good or poor life. The paper shows how the question of time, and particularly the acceleration of pace of life, is vital for modern sporting performance.
\end{abstract}

\section{Keywords}

acceleration of pace of life, high-level, performance, sport, time constraints

\footnotetext{
Corresponding author:

Helene Joncheray, Laboratoire Techniques et Enjeux du Corps (EA 3625), Sports Sciences Faculty, Paris Descartes University - Sorbonne Paris Cité, I rue Lacretelle, 75015 Paris, France.

Email: helene.joncheray@parisdescartes.fr
} 


\section{Introduction}

In a rising competitive sporting environment between nations (De Bosscher et al., 2008), we are wondering about the conditions related to high performance (Demazière et al., 2015) and more precisely about the pace of life of French high-level athletes. Athletes' pace of life (Robinson and Godbey, 1999; Rosa, 2013) can be defined in two steps. On the one hand, athletes are faced with different time constraints such as training, competition, recuperation, care, study, family and sociability, which determine a schedule of activities to be completed. On the other, athletes have the feeling that they will be able to face the joint achievement of these constraints, or not. However, the conditions for high performance have changed considerably over the last few years. Athletes must spend more time training and competing (Bullock et al., 2009), and devote a lot of time to mental, physical and nutritional professionals (Mignon and Lemieux, 2006). Furthermore, they must continue to respond to some constraints such as studying, spending time with their families, friends, and having sentimental lives (Godber, 2012). In this context, we wonder about the capacity of elite athletes to combine all these constraints, namely to manage the acceleration in their pace of life (Rosa, 2013) in order to be able to achieve always more and better in the same time unit. In order to address this issue, we have studied the French high-level athletes who train at the National Institute of Sport, Expertise and Performance (INSEP).

In France, sports policies are characterized by the strong intervention of the State. As a result, this takes the form of a policy that provides services such as human resources (Honta and Juhle, 2015), regional training centers (CREPS), national schools (equestrian, skiing and sailing) and a multi-sport center, INSEP. The institute (INSEP), is a public establishment depending on the French Ministry of Sport. Its mission is to be at the service of high performance. The institute welcomes 25 national training centers, 'pôles France', for around 600 athletes. At each Olympiad, athletes training at INSEP win about half the total number of French medals.

INSEP is characteristic as it is not only a training center but also a medical center, a place for education and a place of residence. The training center provides the French teams with sports facilities dedicated to each sport and also a wide range of activities: physical preparation, mental preparation, recuperation, nutrition and rehabilitation. Numerous educational pathways are provided at INSEP (secondary education, higher education and a two-year degree). Moreover, partnerships with other schools and universities located near INSEP have been set up. A team is dedicated to professional inclusion for athletes seeking a job. Lastly, INSEP provides accommodation, areas for relaxation and a restaurant to 400 athletes.

The objective of having everything available in one place aims at providing all the services necessary to athletes to achieve a successful dual career both in sport and education (Debois and Leseur, 2013). Each of these 25 centers organizes its performance project in complete autonomy by choosing among the proposed activities - outside of the training - the one(s) it wishes to integrate. In order to benefit from these activities, the sports federations make financial contributions to INSEP. Even if projects are coordinated between the centers and INSEP, high-level athletes then depend on the center's injunctions for their sports project and on the INSEP's for their training programs. That 
is why INSEP is a particularly relevant subject of study to give insights into the issue of the pace of life of high-level athletes.

\section{INSEP and the dramatic rise in sporting constraints}

INSEP has not escaped the professionalization process, i.e. the division of the coach's labor (Mignon and Lemieux, 2006). This process has led to the emergence of numerous experts who claim their ability to enhance the performance of high-level athletes. As a result, those professionals claim a right to have time to give their expertise. Thus, progressively the recourse to experts has been institutionalized at INSEP and this phenomenon has caused the introduction of their expertise in the athletes' temporality. Mental preparation, physical preparation, rehabilitation are part of the organizational plans for high-level sport. Two kinds of situation arise: either the centers include these activities in the time devoted to sports training and thus reorganize their athletes' temporality; or these activities are an opt-in for athletes who in this case have to add these specialists' interventions to the time they devote to training.

The problem is all the more complex as in parallel the volume of training has dramatically increased. In 1990, 41\% of INSEP's athletes trained less than 10 hours per week and 59\% trained 10-20 hours (Irlinger et al., 1990). Today, very few athletes train for less than 20 hours per week. Numerous international studies have confirmed the same phenomenon, i.e. there is an increase in the volume of training hours to be completed in order to remain efficient (Bullock, 2009; Starkes, 2000). Moreover, in France, unlike in other countries (ECA Debois and Leseur, 2013; Van Rens et al., 2015), a high-level athlete is subject to the dual career constraint (Stambulova and Ryba, 2013). Therefore, the organizational plan given to athletes must take into account both their sporting and academic career. Both careers must be well combined in order to enable athletes to be successful, although this seems sometimes rather challenging (Bretschneider, 1999). Since the Mazeaud law dated 29 October 1975, 'Dual Career' is now written as one of the conditions to respect in order to produce high performance (Honta, 2007).

Lastly, the number of training camps is also rising very significantly, which causes very frequent journeys outside INSEP and impacts pace of life considerably. Moreover, the introduction of a ranking in numerous sports has caused a considerable rise in the number of competitions to take part in so as to secure the best possible place and have the best chances of accessing top rankings in the best international competitions. These long periods devoted to training camps and competition tend to reduce considerably the time available for other activities.

Consequently, the professionalization of sports performance management has caused a significant increase in the time available to it. This transformation has raised concerns. An athlete has desires and needs, just like anyone else. He/she may also want to earn his/ her living, lead the social life that their peers have (outings, participation in social networks owing to the new IT), maintain close relationships with the family and have a emotional life. An athlete is in interaction with different social worlds which are more or less important to him/her (Godber, 2012). Yet, each dimension has specific time constraints which belong to his/her pace of life. Although an athlete cannot indulge in these 
activities thoroughly, he/she must constantly adjust them, suppress some, and reduce others in order to find minimum time for himself/herself.

Owing to the amplification and rise in the constraints on athletes to manage their time to reach their sporting objectives, it seems relevant to question the different temporalities prevailing in their pace of life. Constraints and resources alike, the importance of those temporalities often depends on the representations of players and on the choices they make in prioritizing these issues to manage their lives. A pace of life is based on a twofold dynamic, i.e. what the environment offers or imposes on an athlete and what he/she is really going to achieve. On the one hand, there are time constraints such as time for training, competition, study, care, family and sociability, which are imposed on him/her. But whether athletes feel they will be able to cope or not with the completion of these constraints has a consequence - they will have to make choices.

\section{Questions}

Except for a report published in 1990 on the pace of life of INSEP's athletes (Irlinger et al., 1990), no recent study in sociology has been carried out specifically on the pace of life of high-level athletes in France. When the topic was addressed, it was only briefly dealt with concerning more general studies, notably related to socialization in sport (Bertrand, 2012; Burlot, 2013; Sorignet, 2006; Viaud and Papin, 2012), but it was never a topic of study per se. A few studies are based on time to explore issues such as injuries (Collinson, 2003; Sorignet, 2006), time management in a discipline (Smith, 2002) or emergency time (Phoenix et al., 2007).

And yet, in a more general way, the time issue is a scientific concern and has long been one (Durkheim, 1912; Elias, 1996), but above all, for 20 years it has been reasserted as a relevant element of social analysis (Bergmann, 1992; Dubar, 2004; Dubar and Thoemmes, 2013; Rosa, 2010a, 2010b, 2013). This enthusiasm testifies to the interest aroused by this notion and also to a concern for a phenomenon which impacts the very foundations of society. Within this sociology of time, the issue related to pace of life is meaningful in Rosa's works (2005, 2010a, 2010b, 2013). Rosa (2013) refers to a social acceleration of time. According to the author, society has entered a post-modern period which, contrary to the preceding ones, places individuals in a race against time. Consequently, they no longer let time fly by; they want to act upon time, striving to accelerate it. Therefore, the natural flow of time is broken by anticipating future times in the present. This acceleration, i.e. this dynamic in which the members of society are urged to achieve more and better within the same time unit, has three different forms - a technical acceleration (time saved thanks to technique, i.e. the Internet, transportation), an acceleration of changes (practices and objects are more and more rapidly questioned) and an acceleration of the pace of life. The latter will more particularly draw our interest in the study of French high-level athletes.

Rosa's reading model of social acceleration (2013) is particularly relevant when analyzing the issue of athletes' pace of life. In order to build it, Rosa (2013) relied on field data (observations, documents, surveys). This model can be used for macrosociological analyses but also through microsociological analyses allowing a discussion of the truth of ideas put forward within specific social groups. 
According to Rosa (2013), the acceleration of pace of life includes two components - an objective and a subjective one. The objective component is characterized by a shortening or a compression in the episodes related to action. It results in an increase in the number of episodes of action per time unit (Rosa, 2013). This acceleration can be observed in four types of adaptative strategies, i.e. acceleration of action (for example reading faster), reduction, even suppression of timeouts and pauses - execution of several tasks simultaneously (multitasking) - and a fourth strategy that is borrowed from Robinson and Godbey (1999) - replacing slow activities with faster activities (travelling faster by plane rather than by train). The subjective component results in the reinforcement of a feeling of urgency, time pressure and forced acceleration. It generates stress and the fear of not being able to cope any longer. The necessity to manage temporalities constantly, efficiently and in anticipation has become an alienating (Rosa, 2010b) condition of contemporary efficiency. Even if technical acceleration, for instance, can be beneficial, it is the interaction of three types of acceleration - technical, change and pace of life - which becomes alienating (Rosa, 2010b): if technical innovations make things quicker, the time saved is systematically used to do more (Rosa, 2010b). Adaptive strategies do not necessarily give individuals respite. The analysis of this acceleration shows that it does not only impact professional life, but it is becoming a true cultural standard - always strive to achieve more in the same time unit, which in this respect is akin to a phenomenon pervading all walks of lives. Experiences are increased and social times superimposed because it is impossible to derogate from this dynamic if one wishes to continue the race. Here, Rosa refers to desynchronization (Rosa and Scheuerman, 2009), unhealthy polarization and a risk of exclusion. On the one hand, some athletes are overworked, but on the other, some are excluded from the acceleration system (Rosa, 2010b).

Although the race for efficient time generates some kind of negative stress under the cover of high performance, Darmon (2013) has shown that in the environment of preparatory classes in the French leading schools (classes to prepare students for the entrance examinations to the top-ranking higher education establishments) the stress is not always negative. It could even be the condition for efficiency as it places individuals in a level of tension, which is favorable to performance. Thus, the most efficient athlete is the one who is able to beat the flowing time, constantly anticipating, always striving to accomplish more in the same time unit (Rosa, 2013). Darmon (2013) coined such students 'time masters' because they are often the most successful in combining their different objectives. Likewise, optimization and urgency play an overriding role in the organization of the sporting lives of athletes-students (Phoenix et al., 2007). Their objective Please check editorial amendment here] is to reach their best-expected level rapidly because they deem that with age and when they start their professional careers, this objective will no longer be possible.

The objective of this paper is to give an insight into how French high-level athletes manage to cope or not with this acceleration of their pace of life by answering the following questions: (1) how do athletes manage to cope with all the temporalities which are imposed on them; (2) can they combine everything or do they need to make difficult choices?

This questioning has twofold relevance - it not only opens a research study perspective on a rarely studied subject in sport sociology but above all, it allows examining a 
social phenomenon, time acceleration. The race for high performance in which the French elite athletes are engaged provides a particularly good illustration of all the tensions at stake.

\section{Methodology}

In order to grasp the consequences of time acceleration, 42 semi-directed interviews were conducted with high-level athletes from INSEP. The interviews were conducted in the continuity of an exploratory pre-survey involving two types of professionals who were part of the athlete's environment. Five collective interviews were conducted with the sports managers and/coaches in charge of INSEP's national training centers ('Pôles') in order to better understand the problems related to the pace of life of the high-level athletes they coach. Seventeen other interviews were conducted with members of staff working in the different support services of INSEP in order to collect their expertise on the issue (Medical Service (3), Education Department (3) Monitoring of the National Training Centers, Supervision of Minors and Adults (3), psychologists (2), dietician (1) Research (2), Reception (1). This first series of interviews enabled to direct both the choice of athletes to be interviewed and the topics to be dealt with in the interview guidelines.

In order to obtain a panel of athletes who represent a variety of situations identified at INSEP, the choice of athletes was set on the necessity to have at least one athlete per national training center and a balanced representation of sports depending on imperatives such as adversity (which implies many trips), training volume, whether athletes are old enough to compete on the international circuit and training location (on INSEP's site or outside). Several criteria were taken into account in order to select the sample: the gender (21 men, 21 women); the age, at least 18 years old (13), 19-25 age range (16) and over 25 years old (13); the status, boarders (26), day athletes (6), athletes who only train at INSEP (10); the socio-professional situation (students, employees); the home town (the Paris region, the provinces, overseas); the situation preceding the enrolment at INSEP (high-level pathway or not); and the level reached (young/confirmed/medalist in World championships or at the Olympic Games). The aim was not to have a representative sample statistically speaking, but a group of athletes who represented the wide scope of conditions identified as relevant in the pre-survey in order to present an exhaustive vision of INSEP's athletes' pace of life. These social determinants guided us in the selection of athletes interviewed. But we chose not to focus our analysis on the issue of social differences and of their consequences on pace of life.

Five interviewers took part in the interviews in order to have multiple visions and also to manage the interviewer/interviewee relationship in the best way. All of the interviewers had previously handled several interviews. One of the reviewers has been a researcher at INSEP for 15 years. This was a definite advantage to have access to a population which is normally difficult to reach owing to media exposure (Glesne, 2011). His influence was not different from the other interviewers' since there is no subordinate relationship between the research department and the poles, or individually between the researchers and the interviewees. All professional ethical precautions were taken in order to facilitate contacts and preserve interview anonymity. We perceived no 
difference in the athletes' attitude. They were very open and didn't have political or cautious discourses.

The interviews were conducted between September 2013 and June 2014. They lasted between 45 minutes and $1 \mathrm{~h} 30$ and addressed the following themes: 1) the situation preceding arrival at INSEP (the athlete's social environment, sporting trajectory, and pace of life); 2) a whole set of questions based on simultaneous temporalities regarding the pace of life at INSEP (objective description, perception, sacrifices, priorities, being late); 3) dual career objectives (sport, education); 4) the different temporalities were systematically dealt with when they had not been addressed before by asking each time about the objective and subjective character of any temporality (sporting time - study and work - trips - meals, sleep, care, recuperation - family, friends, sentimental life, leisure, time to kill). The interview guide complied with scientific rules (Patton, 2002).

The complete transcripts of the interviews were done and analyzed one by one according to the themes emerging from the questioning (Paillé and Mucchielli, 2012). We then carried out a transversal synthesis about each theme on the basis of the various interviews.

We chose to focus this paper on the transversal elements, making it possible to discuss the acceleration of pace of life objective et subjective nature developed by Rosa. We will thus not develop the issue of the diversity of pace of life's objective and subjective conditions depending on the athletes' social determinants.

\section{Results and discussion}

First, we analyzed how athletes experience the acceleration of their pace of life, what Rosa (2013) defined as the constituents of a pace of life. Then, we described the adaptive strategies set in place by athletes to get prepared for such acceleration, i.e. the kind of difficult decisions made according to the objective component.

\section{Athletes on the verge of a good or poor life, on a knife-edge}

A differentiated and paradoxical perception of pace of life. The analysis of athletes' discourse shows that there is a high heterogeneity in their pace of life. Their discourse is based on different situations depending on the sport, on the type of studies, on their situation as athletes (boarders or not), whether their training center is far away or not, and on the journeys from one venue to another. This heterogeneity not only concerns the objective dimension of pace of life but also the subjective dimension. One's age, performance level, length of time spent at INSEP or having been through a center before entering INSEP play a very important role in the perception of one's pace of life, suggesting the existence of a learning process throughout one's career (Hughes, 1984). Newcomers, for instance, all say they had a hard time with the new pace of life they were faced with for varying lengths of time. These perception differences about one's pace of life even seem paradoxical at times. As a matter of fact, those who do not cope very well with their lives as athletes are not those who objectively have busier schedules (training loads and study time) and vice versa. All the athletes who were interviewed and have experienced the attractive possibility of living only for sport and have stopped their studies for a year 
(such arrangement is sometimes allowed under certain conditions) have admitted that they did not live very happily during that period because of the boredom and the stress caused by staking everything on sport. This is precisely what a female athlete explained:

It is better to do something else, but not only sport. Last year, it was the first time I had nothing else to do, which was strange, so generally I don't like this very much. I prefer to have something else to do, even when I have very little to do because I am not used to doing nothing... Honestly, you get bored, that's why some athletes blow a fuse and prefer to go back to training very quickly because they have nothing else to do. (A female athlete, aged 28, a medalist)

This situation refers to a form of organizational imperative, which arises when the schedule becomes busy and which generates some kind of positive stress (Darmon, 2013). In a study about elite collegiate athletes' emotional life, McAllister et al. (2001) had already highlighted the fact that their lifestyle is characterized by a permanent energy discharge. Conversely, having some free time can lead to take (too much) time. In order to avoid this problem, athletes generally tend to lengthen their schooling (Burlot and Mignon, 2014).

Conversely, this does not necessarily mean that busy schedules are always well accepted. Numerous overtraining even quasi-burnout situations can be perceived in the interviews on the alienating consequences (Rosa, 2010b) of the acceleration of pace of life, hence the idea of some kind of negative stress. But this also highlights the fact that athletes dislike periods of inactivity, as well as the periods when they have time to kill, just like this weight-lifter (a male weight-lifter, aged 23): 'This year, the situation has been a little challenging because I have stopped studying and, as a result, the days seem long. I get bored and so I tend to think too much... Apart from training, I don't do anything.'

Therefore, it seems necessary to maintain some kind of tension to find the right balance between an overloaded schedule and an extremely light one in order to be efficient in sport. The analysis of all the athletes' discourse suggests that those who better cope with their pace of life and who are able to endure very heavy schedules are often those who are able to set up personal strategies to better optimize the combination between all the temporalities which compose their lives. The interviews show that autonomy and responsibility are dispositions often present in these athletes.

The time master figure. It emerged that the athletes who were interviewed are often endowed with a strong organizational maturity. This competence stands out significantly, as high-level athletes are particularly well organized and are 'time masters' (Darmon, 2013). Just like students from preparatory schools (classes to prepare students for the entrance examinations to the top-ranking higher education establishments), they control the organization of their time. They are rational and rigorous in the definition and combination of the different temporalities which determine their lives based on sporting performance. This maturity is systematically present in the interviews and seems to be related to sporting performance. The ability to manage one's time, to organize and to shape it seems to be a strong characteristic in the champion's figure.

(...) When I am on a training camp, I know that it's going to be alright but when I am here, I waste quite a lot of time and I do the same at the weekends, [...] At this very moment I tell 
myself that with more organization, even if it makes life more difficult, even if I must take two hours every Sunday evening to get a glance of my weekly schedule, I must do it because this is going to help me save 3 to 4 hours in the week. (A male paddler, aged 22)

Being involved in a sporting career develops maturity regarding organization, namely for school work (Darmon, 2013). Therefore, even though high-level athletes are less engaged in their academic plan than in their sporting plan, they give evidence that they are quite significantly efficient both in school and university work. This finding could account for their good professional inclusion after their sporting careers (Conzelmann and Nagel, 2003; Curtis and Ennis, 1988; Eisen and Turner, 1992).

In this context of rationalization (Viaud and Papin, 2012), a race for maximum efficiency in time management is engaged; it is a chase against waste where time waste is often synonymous with discomfort and inefficiency.

$\mathrm{X}$ : We have class from 8 to 10 am and from 2 to $4 \mathrm{pm}$, and so twice a week. This is perfect for training because I can fit in everything I want, from 8 to 10 am and from 2 to $4 \mathrm{pm}$. I can train at $10 \mathrm{am}$, this is what I do, so I get up at $6.50 \mathrm{am}$, leave home at $7.30 \mathrm{am}$; I use my bike, and as I am always a little late, I manage to arrive exactly on time at $8 \mathrm{am}$.

Consequences: athletes on a knife-edge. This permanent quest for efficiency often places athletes in just-in-time management methods (Delanay and Madigan, 2015). Thus, they may organize their schedules with ideal millimeter accuracy contours, yet this approach no longer leaves room for any timeout and the least gap generates tension or overwork. This also applies to the same rower who arranged a barely tolerable schedule. All possible arrangements have been modulated. Everything has been imagined with a very tight schedule not to waste time and to implement only useful time. In the end, she finds herself in a situation where she feels unhappy (with no possible social life). In her case, there are barely any restorative perspectives, namely any moments when you know you will be able to let off steam a little. But as in any 'passion job' (Freidson, 1986; Laillier, 2011; Perreault, 1988), her sports performance objective leads her to keep on, to resist the fleeting desire to quit and to overcome her suffering (Burlot, 2012; Sorignet, 2006).

X: I get the impression that I am always rushing about all the time. When I prepare my schedule, I include my courses and I copy exactly my boat training program, or rather my rowing training and normally, I should leave some time for social activities but in fact, I don't. I fill all my time with the work I have to do, in fact I really feel overloaded with work.

\section{Y: What have you reduced for example?}

X: Time to watch films. I don't remember when I last went to the cinema. I need a haircut but as it's not urgent, I haven't had one for 3 or 4 months since I decided that I needed one. I don't know which exhibitions I'd like to see in Paris... moreover, I'd just like to spend some time with my family. (A female rower, age 22)

Conversely, some athletes who are 'time masters' are able not to be overwhelmed by this wild race for efficiency. In their work about high-level athletes' discourses, Douglass 
and Carless (2014) give the example of Alex, a multiple Olympic medal holder who doesn't always put sports temporality first: 'Alex puts happiness before performance; places maintenance of friendships alongside or ahead of training; believes there is more to life than just " "swim, swim, swim", (Douglass and Carless, 2014: 144). Athletes with this profile subtly manage to combine all their temporalities. Two elements seem to contribute to such serenity. On the one hand, they are able to clearly prioritize their tasks, which enable them to sacrifice without any predominant emotion in case of necessity. On the other hand, they are able to make time arrangements for regeneration, namely periods which can vary in length in order to recharge their batteries. Naps, sleeping in at weekends, holidays and different kinds of sociability (Crosnoe, 2001) can be mobilized for this purpose as this athlete explained: 'At weekends, I like to sleep in and sleep late because I feel I have a lack of sleep. Like that, I can catch up because we get up late, very late; we get up at about one pm' (a male judoka, age 20). These athletes who manage to make time for regeneration and set priorities are often older and have more experience.

\section{The adaptive strategies implemented by athletes}

What characterizes most athletes in their quest for maximum efficiency in time management is less the fact that they strive to accelerate the completion of actions (even though some use their bikes to go fast around INSEP as an example), but rather that they set up adaptive strategies that are related to the organization of all their temporalities. With the exception of athletes near the end of their career, the thing that characterizes the primary objective of most of the athletes at the INSEP is sports performance. Thus, we have managed to bring about two kinds of strategies that enable us to discuss the adaptive strategies that are implemented by athletes (Rosa, 2013), namely arrangement strategies (to foresee the optimal organization of the different temporalities which compose their pace of life) and adjustment strategies (to be able to adjust temporalities according to different kinds of contingencies).

The temporality arrangement strategies. The arrangement strategies implemented by athletes are part of a kind of anticipatory management of the pace of life in which four different forms can be differentiated: delay/anticipate, superimpose, suppress/reduce some temporalities and replace slow activities with fast activities.

The first strategy, which does not appear in those presented by Rosa (2013), aiming at delaying and anticipating consists in combining temporalities according to different scales by alternatively placing yourself in a short time period and a long one, as for example following a training course by default and postponing the desired training program, because it is incompatible with high-level sport, or sacrificing family life in some periods to live it more intensely at other times. The same holds true for the wrestler who divides his life into two periods, one period is devoted to his practice as follows:

I know that if I qualify for the Olympic Games, I will have a training camp in the summer, so I will only focus on my training. I will call my wife and my little daughter to get some news. However, concerning administrative business, I won't do anything. I can easily ignore it and concentrate on my weight, on my event. (A male wrestler, age 33, a medalist) 
The other period below is devoted to his family where he can be a father or a husband again, as it is expected in any family life. 'In the evenings, I take care of my little girl I bathe her, feed her but my wife cooks for us'. Regarding education, Debois et al. (2015) showed that even if schooling is viewed positively by male athletes as far as the sports identity construction is concerned, it is perceived as a constraint around major events (Debois et al., 2015) and can then constitute an arrangement variable.

Another strategy for optimizing time is based on superimposed temporalities, which is the simultaneous completion of tasks or multitasking (Rosa, 2013). Godber (2012: 10) has already observed this strategy with an athlete who 'conscientiously completed school work during flights'. Thus, several interviews enable us to state that when athletes are faced with limited time capital, they try to superimpose temporalities of different types and purposes in order to save time and, as a result, get maximal efficiency in the management of temporalities such as warming-up while travelling, sleeping or eating while in class... or balancing sport with family life just like this badminton player who changed clubs for a closer club to her home town to be able to see her family more often.

I played in Bordeaux before, things went on very well but I wanted to ... as I was saying, since we have a heavy schedule, I was fed up... Because I am a family woman, friendship is important to me so in fact it was the opportunity to go home and see my friends on a more regular basis. And, at the same time, I was able to play the interclub matches, as planned!!! (A female badminton player, age 25)

Furthermore, in order to organize their schedules, athletes also reduce, sometimes suppress, some temporalities. Therefore, the objective is not simply to reduce or suppress time-off or breaks as Rosa presented it (2013), but rather to act directly on all the temporalities that do not appear as priorities regarding sporting performance. Godber (2012: 7) puts forward the intricate blend which constitutes the management of the time young athletes devote to school and to sport in New Zealand. The same goes for French athletes. Consequently, many athletes spread their studies in order to achieve a dual career (sporting career and education) because the arrangement is offered at INSEP in the post-baccalaureate educational pathways. This synchronized swimmer illustrates this point:

Currently, I study physiotherapy, in second year. So, I have spread the first year to be able to balance training and studies. This year, I'm doing the second year in one year. (A female pentathlete, age 26 , medalist)

Many athletes also report that they suppress what could be called satellite sporting temporalities such as recuperation, or activities such as briefing/debriefing as exemplified by this athlete:

Some athletes can indulge in spending more time at the training session to discuss with the coach, to take 10 minutes or a quarter of an hour but I can't, I have to go straight away. (A male kayaker, age 22)

Finally, athletes are also engaged in a dynamic aiming at replacing slow activities with fast activities. There are commonly used practices such as cold baths to allow muscles to 
recover faster but also the use of nutritional supplements to replace breakfast in the morning as those practices reduce the time usually devoted to those temporalities.

I often use nutritional supplements such as the Lactel supplement because it is convenient; it enables me to have breakfast quickly in the morning while ensuring that I have all the necessary nutrients. (A male weight-lifter, age 23)

The temporality adjustment strategies: adaptive strategies for emergencies. Although arrangement strategies refer to the notion of the anticipative management of pace of life, the adjustment of temporalities is done from day to day. This approach allows a better combination of temporalities according to the athlete's state. These strategies are implemented to harmonize the pace of life when time is short as opposed to longer periods. Athletes are faced with temporalities where they know that they will be able to act immediately to respond to unanticipated needs, changes, or a state of fatigue. These adjustment variables are mostly used to manage periods which are temporally busy such as competitive periods. Generally speaking, athletes act on most temporalities without exception in order to be able to adapt to these changes. Admittedly, a certain number of temporalities may be preferred.

Sporting time. Athletes rarely scale it down with this variable because it induces a feeling of culpability for not having maximized their chances of success (Phoenix et al., 2007). As athletes have a strong desire for success, most of the time they tend to increase sporting time - they can train at weekends or stay longer after training (Delanay and Madigan, 2015; Viaud and Papin, 2012).

In order to succeed, it is necessary to train. Afterwards, my objectives were higher as I contemplated becoming an Olympic champion. It was more challenging but I was always trying to do more than the others. However, I got fatigue problems due to that as I was training all the time (...) I trained at weekends (...) I continued for 20 minutes after training to do my sit-ups as I have back problems (...) (A male boxer, age 29, medalist)

Although an athlete's time in its most restrictive vision - training - rather tends to be corrected and extended, it appears from their discourse that the more distance they take from this core activity, the less value the activities tend to have in their eyes. Indeed, they are largely used as adjustment variables capable of providing time. The same applies to warming-up or stretching, recuperation but also physical or mental preparation. Consequently, it seems difficult for many athletes to find time for mental preparation; they can even cancel an appointment or do not necessarily engage themselves in physical preparation when the coach does not deliver it. As to recuperation, it is frequently used as an adjustment variable to gain time. The higher the athletes' age, the length of time they have been around and their performance level, the easier it seems for them to implement this type of adjustment.

Time for study and other social times: permanent adjustment variables. Apart from being a much mobilized element in athletes' arrangement strategies (suppression, spreading of 
years, alibi studies in order to be able to engage totally in a sporting career plan), studies appear very regularly as a privileged adjustment variable, particularly for boys. Girls display a stronger attachment to studying, which becomes a problem when they have to scale down their engagement in this temporality. Forté and Menesson (2012) also showed that the attachment to this temporality was intimately tied to the athletes' cultural capital. The adjustment function of studies enables to manage the combination of temporalities on a daily basis because athletes can afford some flexibility in this activity as opposed to training strictly speaking. Many high-level athletes admit that they either arrive late for courses, or do not attend courses whereas they would never do so for training. Recuperation is often at stake behind this flexibility because it enables to gain time for sleep.

X: you can't miss training, objectively you can’t do that, (...), but you can manage to miss courses..., for example, this morning, I did not go to class because I was sick during the night and couldn't get up this morning, so I just didn't go. In fact, we miss class more often because we can't miss training, otherwise coaches yell at you (...) as to class, you are reprimanded, you have to justify your absence, yet. (judo, male, age 20)

Lastly, the different times related to athletes' sociability- love, family, and friends - as well as recuperation and meals are also much taken advantage of to manage the difficult times when it is necessary to find time, just like the skater who has breakfast on the way, not to have to go to the self-service whenever he goes to bed late in order to maintain his sleeping time.

\section{Conclusion}

The time periods and particularly the acceleration of pace of life are vital for sporting performance. An athlete seems to be endowed with organizational maturity, i.e. he/she is a strategist in life organization. In order to meet his/her performance objective, he/she develops strategies aimed at making the time they have wholly useful and efficient. He/ she arranges carefully the temporalities he/she is faced with; furthermore, he/she plays with the adjustments in immediacy.

Our results highlight a close relationship between performance, autonomy and acceleration of pace of life. Although it was possible to say in the modern period (Rosa, 2013) that an athlete was somehow affected by his/her trajectory, today it is acknowledged that an actor constantly strives to control his/her fate maybe as one of the consequences of social time acceleration. Athletes have not escaped from this situation either. In order to stay ahead in the race to high performance, an athlete must control his/her pace of life and implement strategies to meet objectives both institutional (what INSEP and his national training center expect from him) and personal (what he/she wishes to do but also what his/her parents wish). According to the objective he/she has set for himself, an athlete seeks solutions, imagines possible arrangements, modulates them, and adjusts them not to waste time and to implement only useful time.

Therefore, athletes seem like self-employed entrepreneurs of their lives, and they manage their enterprises when they mobilize such resource or when they contact such person to reach their objectives. However, are they really free or are they subject to this 
acceleration? The freedom of an athlete consists in acting on his/her commitment in each temporality. He/she is both subject to the rationale of each temporality and actor in the sense that he can decide whether he engages or not with the consequences that any kind of disengagement can cause. As an example, the fact that an athlete decides to reduce or even stop his/her studies inevitably has consequences, which refer to the question of identity.

As a matter of fact, athletes have constraints owing to the system but they also prioritize a certain number of actions while striving to maintain a kind of equilibrium between themselves and the different social worlds in which they interact. Under these conditions a particularly subtle game is played. Whenever there is a risk of desynchronization (Rosa, 2013), athletes have to take greater responsibility and control of their lives, and have to take decisions faster. What is at stake here is to empower athletes to become time masters (Darmon, 2013) in order to sacrifice what they deem less vital, and give value to what can help them meet their needs and to become an autonomous and responsible athlete.

The high-level sport sphere perfectly illustrates the theses developed by Rosa (2005) about the social acceleration of time. It even questions this acceleration's driving forces. For Rosa (2005), there are three of them: (1) an economic driving force: to produce more in the same time; (2) a cultural driving force: to always do more as a synonym for "good life"; (3) a sociocultural driving force: to temporalize time by prioritizing certain temporalities. The performance athletes live for can help better understand this phenomenon of time acceleration. At the origin of this change of pace there always lies, in the athletes' discourse, a meta driving force, that of being the best performing. The reasons can admittedly be economic, cultural or sociocultural, but what animates these driving forces is the relentless pursuit of performance (Ehrenberg, 1991). In terms of perspectives, this qualitative stage highlights quite a few observations and transversal processes about pace of life but leaves some issues unsolved. A quantitative study could help measure the people involved in these issues, and precisely describe their profile. It would thereby make it possible to precisely answer the question pertaining to these pace of life' social provisions and structural conditions.

\section{Funding}

The authors received no financial support for the research, authorship, and/or publication of this paper.

\section{References}

Bergmann W (1992) The problem of time in sociology: An overview of the literature on the state of theory and research on the 'sociology of time', 1900-82. Time \& Society 1: 81-134.

Bertrand J (2012) La Fabrique Des Footballeurs. Paris: La Dispute.

Bretschneider W-D (1999) Risks and Opportunities: Adolescents in Top-Level Sport \&ntilde; Growing Up with the Pressures of School and Training. European Physical Education Review 5(2): 121-133.

Bullock N, Gulbin JP, Martin DT, et al. (2009) Talent identification and deliberate programming in skeleton: Ice novice to winter Olympian in 14 months. Journal of Sports Sciences 27(4): 387-404.

Burlot F (2012) La carrière en boxe anglaise. In: Bercot R, Divay S and Gadéa C (eds) Les groupes professionnels en tension. Frontières, tournants, régulations. Toulouse: Octares, pp.245-262. 
Burlot F (2013) L'univers de la boxe anglaise. Sociologie d'une discipline controversée. Paris: Les éditions de l'INSEP.

Burlot F and Mignon P (2014) Are elite sport and academic achievement compatible? Lessons from INSEP's socio-demographic database. In: ISSA world congress of sociology of sport, Beijing, China, 9-13 July.

Collinson JA (2003) Running into injury time: Distance running and temporality. Sociology of Sport Journal 20: 331-350.

Conzelmann A and Nagel S (2003) Professional careers of the German Olympic athletes. International Review for the Sociology of Sport 38(3): 259-280.

Crosnoe R (2001) The social world of male and female athletes in high school. In: Kinney DA (ed.) Sociological Studies of Children and Youth. London: Emerald Group Publishing Limited, pp.89-110.

Curtis J and Ennis R (1988) Negative consequences of leaving competitive sport? Comparative findings for former elite-level hockey players. Sociology of Sport Journal 5: 87-106.

Darmon M (2013) Classes préparatoires. La fabrique d'une jeunesse dominante. Paris: La Découverte.

Debois N and Leseur V (2013) Athletes' careers in France: In pursuit of excellence in sport and life. In: Stambulova TV and Ryba NB (eds) Athletes' Careers Across Cultures. New York: Routledge, pp.90-102.

Debois N, Ledon A and Wyllman P (2015) A lifespan perspective on the dual career of elite male athletes. Psychology of Sport and Exercise 21: 15-26.

De Bosscher V, Bingham J, Shibli S, et al. (2008) The Global Sporting Arms Race: An International Comparative Study on Sports Policy Factors Leading to International Sporting Success. Oxford: Meyer \& Meyer.

Delanay T and Madigan T (2015) The Sociology of Sports: An Introduction. 2nd ed. Jefferson, NC: McFarland.

Demazière D, Ohl F and Le Noé O (2015) La performance sportive comme travail. Sociologie du travail 57(4): 407-421.

Douglass K and Carless D (2014) Life Story Research in Sport: Understanding the Experiences of Elite and Professional Athletes through Narrative. London: Routledge.

Dubar C (2004) Présentation du numéro Un. Temporalités 1, mis en ligne le 23 juin 2009. Available at: http://temporalites.revues.org/539 (consulté le 25 mars 2016)

Dubar C and Thoemmes J (2013) Les temporalités dans les sciences sociales. Toulouse: Octarès.

Durkheim E (1912) Les formes élémentaires de la vie religieuse. Le système totémique en Australie. Paris: Les Presses universitaires de France.

Eisen G and Turner D (1992) Myth and reality: Social mobility of American Olympic athletes. International Review for the Sociology of Sport 27: 65-75.

Elias N (1996) Du temps. Paris: Fayard.

Ehrenberg (1991) Le culte de la performance. Paris: Calmann-Lévy.

Forté L and Menesson C (2012) Réussite athlétique et héritage sportif. SociologieS (Théories et recherches), mis en ligne le 15 novembre 2012. Available at: http://sociologies.revues. org/4082 (consulté le 25 mars 2016).

Freidson (1986) les professions sociologiques comme défi à l'analyse sociologique. Revue Française de Sociologie XXVII(3): 431-443.

Glesne (2011) Becoming Qualitative Researchers. Boston, MA: Pearson.

Godber K (2012) The life worlds of elite young athletes: A lens on their school/sport balancing act. The New Journal of Gifted Education 17(1). Available at: http://www.giftedchildren.org. nz/apex 
Honta M (2007) Organising the dual sporting-social project for high level athletes in France: The difficulties of learning of collective action. International Review for the Sociology of Sport 42(2): 133-148.

Honta M and Juhle S (2015) Serving the state and the private sector: The paradoxical effects of the reconstruction of public action on the career path of sport ministry agents in France. International Review for the Sociology of Sport 50(2): 179-195.

Hughes E (1984) The Sociological Eye: Selected Papers. New Brunswick, NJ: Transaction Publishers.

Irlinger P, Louveau C and Metoudi M (1990) Temps et Rythme de vie des INSEPIENS. Report for the département du sportif de haut niveau, Mission recherche, Paris: Laboratoire de Sociologie du Sport.

Laillier J (2011) La dynamique de la vocation. Les évolutions de la rationalisation de l'engagement au travail des danseurs de ballet. Sociologie du travail 53(4): 493-514.

McAllister DR, Motamedi AR, Hame SL, et al. (2001) Quality of life assessment in elite collegiate athletes. American Journal of Medicine 29: 806-810.

Mignon P and Lemieux C (2006) Etre entraîneur de haut niveau. Sociologie d'un groupe professionnel entre marché du travail fermé et marché du travail concurrentiel. Paris: Report for le Ministère des sports et la préparation olympique.

Paillé P and Mucchielli A (2012) L'analyse qualitative en sciences humaines et sociales. Paris: Armand Colin.

Patton (2002) Qualitative Research and Evaluation Methods. Thousand Oaks, CA: SAGE.

Perreault M (1988) La passion et le corps comme objet de la sociologie: la danse comme carrière. Sociologie et sociétés 20(2): 177-186.

Phoenix C, Smith B and Sparkes AC (2007) Experience and expectations of biographical time among young athletes: A life course perspective. Time \& Society 16(2-3): 231-252.

Robinson J and Godbey G (1999) Time for Life: The Surprising Ways Americans Use Their Time. 2nd ed. University Park, PA: Pennsylvania State University Press.

RosaH (2005) Beschleunigung. Die Veränderung der Zeitstrukturen in der Moderne. Frankfurt am Main: Suhrkamp (zugleich Habil.-Schrift, Univ. Jena 2004).

RosaH (2010a) Alienation and Acceleration: Towards a Critical Theory of Late-Modern Temporality. Malmö: NSU Press.

RosaH (2010b) Accélération. Une critique sociale du temps (traduction Didier Renault). Paris: La Découverte.

RosaH (2013) Social Acceleration: A New Theory of Modernity. Columbia: Columbia University Press.

RosaH and Scheuerman W (eds) (2009) High-Speed Society: Social Acceleration, Power, and Modernity. University Park, PA: Pennsylvania State University Press.

Smith G (2002) Racing against time? Aspects of the temporal organization of the runner's world. Symbolic Interaction 25: 343-362.

Sorignet PE (2006) Danser Au Delà de La Douleur. Actes de La Recherche En Sciences Sociales 3(163): 46-61.

Stambulova NB and Ryba TV (eds) (2013) Athletes' Careers Across Cultures. New York: Routledge.

Van Rens FECA, Elling A and Reijgersberg N (2015) Top talent School in the Netherlands: A retrospective analysis of the effect on performance in sport and education. International Review for the Sociology of Sport 50(1): 54-82.

Viaud B and Papin B (2012) Temps sportif, santé du champion et logique de l'urgence. STAPS 2(96-97): 9-27. 